\title{
Parametric Optimization and Experimental Validation for Nonlinear Characteristics of Passenger Car Suspension System
}

\author{
Avesh Mohd $^{1 *}$, Rajeev Srivastava \\ ${ }^{1}$ Mechanical Engineering Department, Motilal Nehru National Institute of Technology Allahabad, \\ Teliyarganj, Allahabad, 211004, India \\ * Corresponding author, e-mail: mail2avesh@gmail.com
}

Received: 15 August 2018, Accepted: 01 February 2019, Published online: 21 May 2019

\begin{abstract}
The study deals with the design of the automotive suspension system to better dynamic characteristics in an uncertain operating atmosphere. Vehicle design parameters are to be optimized to achieve better passengers comfort, vehicle body stability, and road holding as the measure of suspension system performance improvement. The design of experiments gives the optimum parametric combination in the domain on the basis of vertical body acceleration data obtained by simulation of a 2-DOF nonlinear quarter car model. Moreover, the nonlinear hysteric behavior foremost design parameters have been characterized through the theoretical and experimental analysis in order to validate the design and to check the analogical viability of the derived model. Finally, the proposed methodology ascertains the optimum design of the suspension system in the time and cost-effective manner. The developed passive design of car suspension system exhibits excellent vibrational characteristics and convinces the acceptable range of vehicle vibration as suggested by ISO-2631-1997.
\end{abstract}

Keywords

design of experiments, ride comfort, full factorial design, vibration control, nonlinear suspension system

\section{Introduction}

Vibrations are quite undesired in the vehicle dynamics and their harmful effect results in the degradation of passengers comfort and ride quality of the vehicle. Prolonged exposure to vibrations can cause major health issues such as hyperventilation (caused by abdominal walls), disorders of the back, osteoarthritis, slipping of disc etc. (Kjellberg, 1990; Nagarkar et al., 2016). International standards (International Organization for Standardization, 1997) suggests a frequency range of 0.5 to $80 \mathrm{~Hz}$, to assess the potential effects of vibration on human body health, and to make comfort perception (Cao et al., 2011). Though the ride comfort is an unquantifiable terminology, it associates with weighted RMS value of vertical body acceleration in vehicle dynamic research (Sharma et al., 2015; Sharma and Chaturvedi, 2016). Higher the RMS value of acceleration meant for the low level of ride comfort. The inconsistent vertical dynamic forces in vehicle cause the break in ground-tire contact, which is generally expressed as the road holding problem (Avesh and Srivastava, 2012).
The suspension system is a vital part of the ground vehicles that vertically fit between body and wheels. Its prime objective is to provide good ride comfort and stability by means of vehicle body isolation from road irregularities (Poussot-Vassal et al., 2008; Yu et al., 2006). Energy transmits from irregular road profile via tires and connecting links, stores initially in springs and further dissipates through the heating and viscous friction effect of dampers (Chi and He, 2008; Sun et al., 2007). Both the spring and damper are key elements of the suspension system that insert in parallel between sprung and unsprung masses (Nagy and Gáspár, 2012; Zuo and Zhang, 2013).

The parameter's setting and optimization is an important concern in the design of a good suspension system. Soft suspension achieves good ride quality by the potential drop in body vibrations but the low spring-damping rates may fall short to provide the adequate sum of normal forces for consistent ground-tire contact. Lack of suspension forces leads to the large suspension travel and ultimately results 
in the poor road holding of the vehicle (Salah et al., 2012). Stiffer or hard suspension system generally exhibits good handling characteristics; that improves the vertical force stability to maintain proper ground contact. The prerequisite and major design objective of the suspension system is to acquire the optimal trade-off amongst these conflicting requirements (Craft et al., 2003; Hyniova et al., 2009).

The extensive research to develop a better design of road vehicle has been carried out in the past years. Some potential research articles on suspension system design and development are being discussed here to develop a good research background of the work. The genetic algorithm approach has been pursued in the literature at a broad level to carry out the vehicle parametric optimization, it is used by the distinguished researchers to obtain the set of optimized parameters. The objective function selection for GA well explained by the Shirahatti (Shirahatti et al., 2008). The quarter car, half car and full car, linear to nonlinear with or without driver seat models have been carried out in the literature to do the analytical study (Avesh and Srivastava, 2019; Nagarkar et al., 2016; Tewari and Prasad, 1999). Another approach named design of experiment (DOE) has been using to identify the sensitive parameters in the domain. Christensen obtained a design by DOE and resulting design has been evaluated through the 7-degree of freedom suspension system model at ADAMS (Christensen et al., 2000).

The literature has been also reported the numerous methods and significance of optimization in the vehicle design. In the literature, identified parameters that significant to the design of a suspension system are sprung mass, unsprung mass, spring-damping rates, and suspension space (Gobbi and Mastinu, 2001; Tamboli and Joshi, 1999). It is also noted that the vertical body acceleration and the tire normal force have so much importance in the development of objective function as explained by Fig. 1 on basis of literature study.

Presented work, is focused on the optimum design of a conventional suspension system with reduced

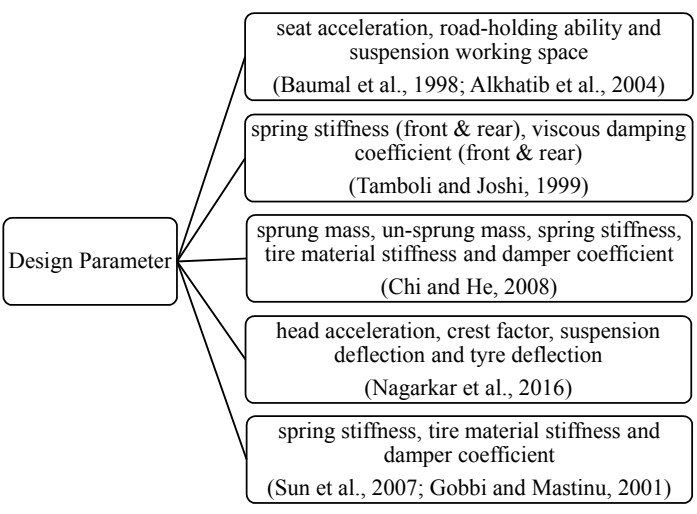

Fig. 1 Objective functions design by reported literature

experimentation time and cost. The broad objective of the work is to develop an optimum design of a suspension system in order to achieve the necessary passenger comfort and vehicle stability. MINITAB ${ }^{\circledR}$ a statistical tool is applied here that comprehend the outcomes achieved by full factorial methodology. Design of Experiments (DOE) is a statistical modeling technique which provides a structured way to control multiple factors having multiple settings (levels) at the same time to understand their impact on the response. DOE provides the facility for comparative design study, screening designs, and response surface modeling (Czitrom, 1999).

Five substantial design parameters described by the chart in Fig. 1, are sprung mass, unsprung mass, spring stiffness, tire stiffness and damping coefficient have been carried out. The search range of parametric values in Table 1 is decided based on the user experience (Alkhatib et al., 2004; Hemanth et al., 2017; Metered et al., 2015).

The nonlinear characteristics of the suspension system elements have been examined by practical and simulation observations. The dynamic behavior of a quarter car suspension system has been estimated through the mathematical model derived from Newton's law of motion. The RMS value of vertical body acceleration obtained from the simulation at the different parametric combination.

Table 1 Search range and parameters

\begin{tabular}{lcccc}
\hline \multicolumn{2}{c}{ Parametric values } & \multicolumn{2}{c}{ Factors with coded levels } \\
\hline Factors & Value & Factors & \multicolumn{2}{c}{ Levels } \\
\cline { 3 - 5 } & & Sprung Mass $\left(m_{s}\right)$ & 250 & 300 \\
\hline Sprung Mass $\left(m_{s}\right)$ & $250 \mathrm{Kg}$ & Max $(+1)$ \\
Un-Sprung Mass $\left(m_{u}\right)$ & $30 \mathrm{Kg}$ & Un-Sprung Mass $\left(m_{u}\right)$ & 30 & 60 \\
Spring Stiffness $\left(k_{s}\right)$ & $14000 \mathrm{~N} / \mathrm{m}$ & Spring Stiffness $\left(k_{s}\right)$ & 14000 & 18000 \\
Damping coefficient $\left(c_{s}\right)$ & $500 \mathrm{Ns} / \mathrm{m}$ & Damping Coeff. $\left(c_{s}\right)$ & 500 & 1000 \\
Tire Stiffness $\left(k_{t}\right)$ & $140000 \mathrm{~N} / \mathrm{m}$ & Tire Stiffness $\left(k_{t}\right)$ & 140000 & 180000 \\
\hline
\end{tabular}


Experimental time and cost have been reduced by utilizing the MATLAB-SIMULINK platform. Section 2 of this paper is devoted to the mathematical modeling and road profile estimation using the nonlinear equations. A quarter car test setup is fabricated in the laboratory and nonlinear behavior of suspension system elements is examined and correlated with practical performance on the developed test rig. Design of experiments full factorial methodology is carried out to the proposed application in Section 3. Section 4 is dedicated to validation of the results on the test rig. The work is concluded after observation and discussions in Section 5.

2 Mathematical modeling and nonlinear characteristics A two degree of freedom quarter car model subjected to random road profile is carried out in the study. There are five key elements- sprung mass, unsprung mass, spring, damper, and tire, comprised by the quarter car model as shown in Fig. 2. Dynamic behavior analysis has been carried out through theoretical and experimental means. The road excitation took place in the course of the ISO-8608 described the rough road surface of E-level (International Organization for Standardization, 1995). Subsequently, the road surface based on Gaussian white noise function has been replicated on the wooden wheel fitted in the test rig. In advance, the nonlinear properties have been added to the theoretical model and further correlated with physical setup characteristics.

\subsection{Theoretical model}

The theoretical model of the passive suspension system used in the simulation is shown in Fig. 2(a). The key parameters of the design are sprung mass, unsprung mass, spring stiffness, damping coefficient as denoted by $m_{s}, m_{u}$, $k_{s}$, and $c_{s}$ respectively (Németh and Gáspár, 2017). The tire behavior is simplified by spring $\left(k_{t}\right)$ and damping $\left(c_{t}\right)$ characteristics. The free vertical motion of sprung-unsprung mass and vertical tire movement are denoted by the $z_{s}, z_{u}$ and $z_{r}$ respectively.

The nonlinear behaviour of the model governs by the equations of the motion Eq. (1)-(6) that are derived by using first principles

$$
\begin{aligned}
m_{s} \ddot{z}_{s}= & F_{s s}\left(z_{s}, z_{u}, t\right)+F_{s d}\left(\dot{z}_{s}, \dot{z}_{u}, t\right) \\
m_{u} \ddot{z}_{u}= & -F_{s s}\left(z_{s}, z_{u}, t\right)-F_{s d}\left(\dot{z}_{s}, \dot{z}_{u}, t\right) \\
& +F_{t s}\left(z_{u}, z_{r}, t\right)+F_{t d}\left(\dot{z}_{u}, \dot{z}_{r}, t\right) .
\end{aligned}
$$

Force produced in the nonlinear spring, the piece-wise linear damper and the tire are formulated by the Eq. (3)-(7). (a)
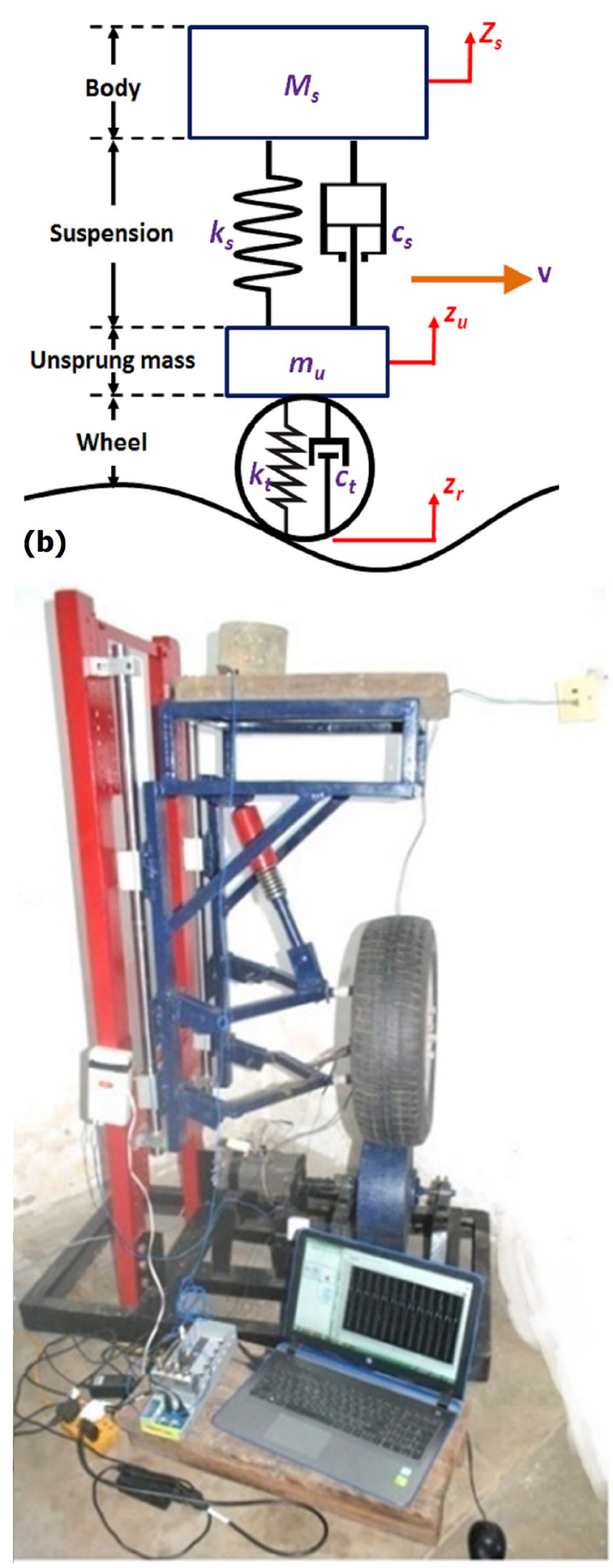

Fig. 2 Quarter car test model (a) theoretical model (b) DAS integrated test setup

$$
\begin{aligned}
& F_{s s}\left(z_{s}, z_{u}, t\right)=k_{s}\left(z_{u}-z_{s}\right)+k_{s n}\left(z_{u}-z_{s}\right)^{3} \\
& F_{s d}\left(\dot{z}_{s}, \dot{z}_{u}, t\right)=\left\{\begin{array}{l}
c_{e}\left(\dot{z}_{u}-\dot{z}_{s}\right) \\
c_{c}\left(\dot{z}_{u}-\dot{z}_{s}\right)
\end{array}\right.
\end{aligned}
$$


$F_{t s}\left(z_{u}, z_{r}, t\right)=k_{t}\left(z_{r}-z_{u}\right)$

$F_{t d}\left(\dot{z}_{u}, \dot{z}_{r}, t\right)=c_{t}\left(\dot{z}_{r}-\dot{z}_{u}\right)$

where $k_{s}$ and $k_{s n}$ are the linear and nonlinear terms for spring rate; $c_{e}$ and $c_{c}$ are the damping coefficients for the extension and compression movements.

The dynamic equations (Eqs. (1) and (2)) are being converting to state space form Eq. (8) through the state variables described in Eq. (7).

$$
\begin{aligned}
& x_{1}= z_{s}, x_{2}=\dot{z}_{s}, x_{3}=z_{u}, x_{4}=\dot{z}_{u}, \\
& \dot{x}_{2}= \eta\left(F_{s s}\left(z_{s}, z_{u}, t\right)+F_{s d}\left(\dot{z}_{s}, \dot{z}_{u}, t\right)\right), \\
& \dot{x}_{3}= x_{4}, \\
& m_{u} \ddot{z}_{u}=-F_{s s}\left(z_{s}, z_{u}, t\right)-F_{s d}\left(\dot{z}_{s}, \dot{z}_{u}, t\right) \\
& \quad+F_{t s}\left(z_{u}, z_{r}, t\right)+F_{t d}\left(\dot{z}_{u}, \dot{z}_{r}, t\right) .
\end{aligned}
$$

Where $\eta=\frac{1}{m_{s}}, \gamma=\frac{1}{m_{u}}$ are the uncertain parameters.

The precise estimation of the road surface is the prerequisite in vehicle design analysis (Sharma and Kumar, 2017a; 2017b). There are many possible ways to characterize the road profile as vehicle excitation input. The shock from bumps and potholes are basically short duration discrete events of high intensity, whereas a rough road creates the vibration with prolonged and consistent excitation that generally applies in vehicle dynamic analysis. Road roughness is generally characterized by power spectral density (PSD) function which classification has been presented in ISO8608 (International Organization for Standardization, 1995).

PSD shows the characteristic drop in magnitude with wave number, the PSD function in frequency and time domains are described in Eq. (9) and (10) respectively.

Road displacement PSD,

$$
\begin{aligned}
& \Phi(\Omega)=\Phi\left(\Omega_{0}\right)\left(\frac{\Omega}{\Omega_{0}}\right)^{-w} \\
& \Phi(n)=\Phi\left(n_{0}\right)\left(\frac{n}{n_{0}}\right)^{-w} .
\end{aligned}
$$

Where $\Omega\left(=\frac{2 \pi}{\lambda}\right)$ the angular spatial frequency in $\mathrm{rad} / \mathrm{m}, \lambda$ denotes the wavelength

$\Phi_{0}\left(\triangleq \Phi\left(\Omega_{0}\right)\right)$ describes the power spectral density in $\mathrm{m}^{2} /(\mathrm{rad} / \mathrm{m})$ at reference wave number $\Omega_{0}=1.0 \mathrm{rad} / \mathrm{m}$ $n=\frac{\Omega}{2 \pi}$ is the spatial frequency at a reference spatial frequency $n_{0}=0.1 \mathrm{cycle} / \mathrm{m}$ $w$ is the waviness, generally for road surface $w=2$

The road surface excitation is characterized through the Gaussian filter in Eq. (11), where $w_{0}$ denotes Gaussian white noise with a PSD of 1 . $\dot{z}_{r}=-2 \pi f_{0} a z_{r}+2 \pi \sqrt{\Phi_{0} \nu w_{0}}$

The transient response of the applied road profile is shown in Fig. 3. The car is considered to be run at the speed (v) of $45 \mathrm{~km} / \mathrm{h}$ at a very poor road of class $E$ with the associated degree of roughness (International Organization for Standardization, 1995).

$$
\Phi\left(n_{0}\right)=4096 * 10^{-6} \mathrm{~m}^{2} /(\mathrm{m} / \text { cycle })
$$

\subsection{Experimental Setup}

The quarter car test setup shown in Fig. 2(b), has been fabricated to form a precise model of the system under study. The setup is integrated with acceleration, speed and displacement sensors supported by NI-data acquisition system. As the operating conditions have a considerable effect on vehicle performance, the test setup incorporated with speed regulation mechanism and provision to change spring, damper and sprung mass. The individual elements, as well as the whole fabricated test setup, have been modeled in Section 2.1 with the added nonlinearities in its behavior. It is noted that the maximum nonlinearity takes place in suspension system at rubber bump stops, tire and spring. Force-displacement test has been carried out on spring and the nonlinear characteristics.

The test setup has been constructed on a simple vertically guided structure of two parallel channels. The steel structure has a total mass of $105 \mathrm{~kg}$ includes the weight of all required components that make it represents approximately a quarter of the vehicle. The structure is guided vertically by frictionless linear slide bearings; the very low Coulomb friction forces counteract the movement of the chassis mass so that the sliding of elements and other joints are considered to be ideally frictionless. There are no rubber-mounts integrated into the setup as used in car chassis to acoustics and vibration-isolation. The steering mechanism has not been added in the setup; the wheel is facilitated with a constrained rolling movement.

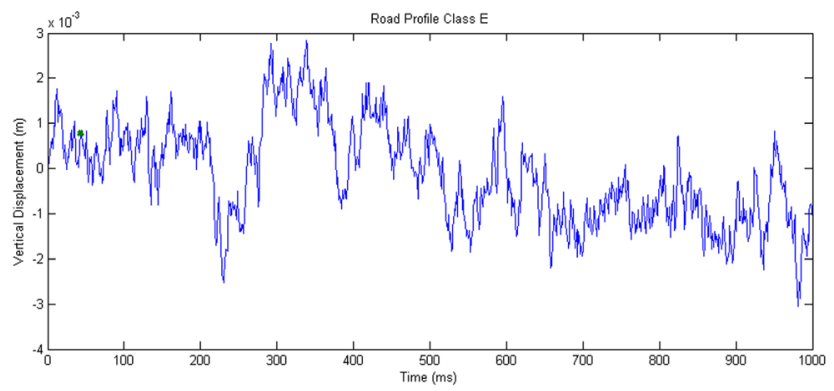

Fig. 3 Road input excitation for rough road of Class E 
The tire excitation is provided by the reverse process through a wooden driven wheel of diameter $300 \mathrm{~mm}$ and width $145 \mathrm{~mm}$ equal to the tread width of the tire of specification 145/70R12. The road profile roughness has been constructed on the periphery of the wooden wheel driven by an electrical AC motor that emulates the road induced vibrations. The vehicle velocity has been imitated by the motor RPM that is controlled by a manual regulating switch. The motor is mounted on the base structure and the long driven rod is guided by a roller bearing in order to avoid lateral forces and torques. The wheel and tire assembly including steel rim is fitted as it is in the car. Further to make the system active controlled, an actuator can be interested in the existing arrangement between the sprung mass and wheel.

Whole system model behavior in terms of vertical body acceleration of sprung mass is represented through the characteristic plots in Fig. 4. The closed correlation, in the behavior of individual elements and system as a whole, with experimental characteristics, confirms the validity of the model and the modeling approach. The model closely replicates the behavior of the actual system hence it is carrying out to further analysis instead of physical setup.

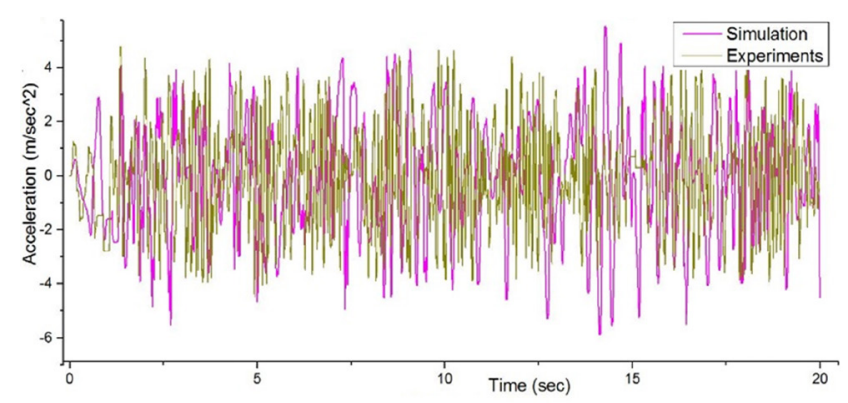

Fig. 4 Nonlinear quarter car suspension system response

\section{Design of experiments}

DOE carry out the multiple factors together that leads to the simultaneous reduction in time, cost and amount of computations. In DOE, the significant factors and their interactions are revealed across all the possible combinations in the domain. The total 64 run of experiments with various combinations of input parameters are obtained by $2^{5}$ full factorial design with two replicates cited in Table 2. Vehicle velocity is taken as the block in DOE that helps to prevent any block effect or effect due to experimental factors. Vehicle velocity and the road surface excitation are taken as same as in nonlinear analysis in Section 2.1 and Section 2.2. All the set of experiments are being applied on

Table 2 Experimental Runs

\begin{tabular}{|c|c|c|c|c|c|c|c|}
\hline \multirow[b]{2}{*}{ Run Order } & \multirow[b]{2}{*}{$\mathrm{m}_{\mathrm{s}}(\mathrm{Kg})$} & \multirow[b]{2}{*}{$\mathrm{m}_{\mathrm{u}}(\mathrm{Kg})$} & \multirow[b]{2}{*}{$\mathbf{k}_{\mathrm{s}}(\mathrm{N} / \mathbf{m})$} & \multirow[b]{2}{*}{$k_{t}(N / m)$} & \multirow[b]{2}{*}{$\mathrm{c}_{\mathrm{s}}(\mathrm{Ns} / \mathrm{m})$} & \multicolumn{2}{|c|}{ RMS acceleration $\left(\mathrm{m} / \mathrm{s}^{2}\right)$} \\
\hline & & & & & & Experimental & Predicted \\
\hline 1 & 300 & 30 & 18000 & 180000 & 500 & 0.3114 & 0.3225 \\
\hline 2 & 250 & 30 & $18000 w$ & 140000 & 1000 & 0.5569 & 0.5789 \\
\hline 3 & 250 & 30 & 14000 & 140000 & 1000 & 0.2458 & 0.2635 \\
\hline 4 & 250 & 60 & 14000 & 180000 & 1000 & 0.4236 & 0.4015 \\
\hline 5 & 300 & 30 & 18000 & 140000 & 500 & 0.2863 & 0.3045 \\
\hline 6 & 300 & 30 & 14000 & 180000 & 1000 & 0.5361 & 0.5377 \\
\hline 7 & 250 & 30 & 18000 & 140000 & 500 & 0.6321 & 0.6432 \\
\hline 8 & 250 & 60 & 18000 & 140000 & 500 & 0.7715 & 0.7265 \\
\hline 9 & 250 & 30 & 18000 & 180000 & 1000 & 0.8436 & 0.8321 \\
\hline 10 & 300 & 60 & 14000 & 140000 & 1000 & 0.5047 & 0.5010 \\
\hline 11 & 300 & 60 & 14000 & 140000 & 500 & 0.1136 & 0.1056 \\
\hline 12 & 250 & 60 & 14000 & 140000 & 1000 & 0.9987 & 0.1025 \\
\hline 13 & 250 & 30 & 14000 & 140000 & 500 & 0.6975 & 0.6932 \\
\hline 14 & 250 & 60 & 14000 & 180000 & 500 & 0.3876 & 0.3798 \\
\hline 15 & 250 & 60 & 14000 & 140000 & 500 & 0.5963 & 0.5961 \\
\hline 16 & 300 & 60 & 18000 & 140000 & 1000 & 0.2222 & 0.2202 \\
\hline 17 & 250 & 60 & 18000 & 140000 & 1000 & 0.1365 & 0.1362 \\
\hline 18 & 300 & 30 & 14000 & 180000 & 500 & 0.2368 & 0.2265 \\
\hline 19 & 300 & 30 & 18000 & 140000 & 1000 & 0.5569 & 0.5654 \\
\hline
\end{tabular}




\begin{tabular}{|c|c|c|c|c|c|c|c|}
\hline \multirow[b]{2}{*}{ Run Order } & \multirow[b]{2}{*}{$\mathbf{m}_{\mathrm{s}}(\mathbf{K g})$} & \multirow[b]{2}{*}{$\mathrm{m}_{\mathrm{u}}(\mathrm{Kg})$} & \multirow[b]{2}{*}{$\mathrm{k}_{\mathrm{s}}(\mathrm{N} / \mathrm{m})$} & \multirow[b]{2}{*}{$k_{t}(N / m)$} & \multirow[b]{2}{*}{$\mathrm{c}_{\mathrm{s}}(\mathrm{Ns} / \mathrm{m})$} & \multicolumn{2}{|c|}{ RMS acceleration $\left(\mathrm{m} / \mathrm{s}^{2}\right)$} \\
\hline & & & & & & Experimental & Predicted \\
\hline 21 & 300 & 60 & 14000 & 180000 & 500 & 0.8888 & 0.8847 \\
\hline 22 & 300 & 30 & 14000 & 140000 & 500 & 1.1365 & 1.1356 \\
\hline 23 & 300 & 60 & 18000 & 140000 & 500 & 0.5367 & 0.5296 \\
\hline 24 & 300 & 30 & 18000 & 180000 & 1000 & 0.4789 & 0.4563 \\
\hline 25 & 250 & 30 & 14000 & 180000 & 1000 & 0.1774 & 0.1801 \\
\hline 26 & 300 & 60 & 18000 & 180000 & 1000 & 0.8632 & 0.8647 \\
\hline 27 & 300 & 60 & 14000 & 180000 & 1000 & 0.4324 & 0.4132 \\
\hline 28 & 300 & 30 & 14000 & 140000 & 1000 & 0.3125 & 0.3045 \\
\hline 29 & 250 & 30 & 18000 & 180000 & 500 & 0.4684 & 0.4596 \\
\hline 30 & 250 & 30 & 14000 & 180000 & 500 & 0.7641 & 0.7796 \\
\hline 31 & 250 & 60 & 18000 & 180000 & 500 & 0.5874 & 0.5936 \\
\hline 32 & 250 & 60 & 18000 & 180000 & 1000 & 0.3647 & 0.3741 \\
\hline 33 & 300 & 60 & 14000 & 140000 & 1000 & 0.4536 & 0.4496 \\
\hline 34 & 250 & 60 & 18000 & 140000 & 500 & 0.7387 & 0.7396 \\
\hline 35 & 300 & 60 & 14000 & 180000 & 500 & 1.256 & 1.2698 \\
\hline 36 & 250 & 30 & 18000 & 180000 & 500 & 0.5986 & 0.6021 \\
\hline 37 & 250 & 60 & 14000 & 180000 & 1000 & 0.5035 & 0.5040 \\
\hline 38 & 300 & 30 & 14000 & 140000 & 500 & 0.9756 & 0.9963 \\
\hline 39 & 300 & 60 & 14000 & 140000 & 500 & 0.2043 & 0.2145 \\
\hline 40 & 300 & 30 & 14000 & 140000 & 1000 & 0.4123 & 0.4210 \\
\hline 41 & 250 & 30 & 18000 & 140000 & 500 & 0.6735 & 0.6832 \\
\hline 42 & 250 & 60 & 18000 & 180000 & 1000 & 0.4761 & 0.4879 \\
\hline 43 & 300 & 30 & 18000 & 180000 & 1000 & 0.5932 & 0.6032 \\
\hline 44 & 300 & 30 & 18000 & 180000 & 500 & 0.3964 & 0.4012 \\
\hline 45 & 300 & 60 & 18000 & 180000 & 1000 & 0.6214 & 0.6321 \\
\hline 46 & 250 & 30 & 18000 & 180000 & 1000 & 0.7965 & 0.8065 \\
\hline 47 & 300 & 60 & 18000 & 180000 & 500 & 0.8365 & 0.8412 \\
\hline 48 & 300 & 60 & 14000 & 180000 & 1000 & 0.2632 & 0.2563 \\
\hline 49 & 300 & 30 & 14000 & 180000 & 500 & 0.4486 & 0.4212 \\
\hline 50 & 300 & 30 & 14000 & 180000 & 1000 & 0.5779 & 0.5896 \\
\hline 51 & 250 & 30 & 18000 & 140000 & 1000 & 0.4598 & 0.4589 \\
\hline 52 & 250 & 60 & 14000 & 140000 & 1000 & 0.9036 & 0.9049 \\
\hline 53 & 250 & 60 & 14000 & 140000 & 500 & 0.5324 & 0.5248 \\
\hline 54 & 300 & 30 & 18000 & 140000 & 1000 & 0.7324 & 0.7145 \\
\hline 55 & 250 & 60 & 18000 & 180000 & 500 & 0.6547 & 0.6987 \\
\hline 56 & 300 & 60 & 18000 & 140000 & 500 & 0.3265 & 0.3269 \\
\hline 57 & 250 & 30 & 14000 & 180000 & 500 & 0.8436 & 0.8563 \\
\hline 58 & 250 & 30 & 14000 & 180000 & 1000 & 0.3956 & 0.3785 \\
\hline 59 & 250 & 30 & 14000 & 140000 & 500 & 0.6831 & 0.7015 \\
\hline 60 & 250 & 60 & 14000 & 180000 & 500 & 0.3067 & 0.3125 \\
\hline 61 & 300 & 60 & 18000 & 140000 & 1000 & 0.2215 & 0.2217 \\
\hline 62 & 250 & 30 & 14000 & 140000 & 1000 & 0.3025 & 0.3296 \\
\hline 63 & 300 & 30 & 18000 & 140000 & 500 & 0.3269 & 0.3478 \\
\hline 64 & 250 & 60 & 18000 & 140000 & 1000 & 0.2354 & 0.2145 \\
\hline
\end{tabular}


a validated nonlinear quarter car model using MATLABSIMULINK platform. The root mean square data of vertical body acceleration are obtained in the range of $0.1136 \mathrm{~m} / \mathrm{s}^{2}$ to $1.256 \mathrm{~m} / \mathrm{s}^{2}$ from the experiments correspond to each possible combination of parameters. The lowest value of acceleration is itself lying over the acceptable limit suggested by ISO-2631-1997 (International Organization for Standardization, 1997). Therefore the significant role of the desired parameters and their interactions is explored in regression analysis to get the best-fitted design through graphical as well as analytical methods.

In the qualitative analysis the extent of parameters influence over response is perceived through the Pareto chart in Fig. 5. Any individual factor or the interaction of factors with t-statistics value (ratio of coefficient and standard error coefficient) extending the reference $t$-line is considered significant. So that the factors $m_{s}, m_{u}, k_{s}$ and interactions like $m_{u}{ }^{*} k_{s}, m_{s}{ }^{*} m_{u}, m_{s}{ }^{*} c_{s}, m_{u}{ }^{*} k_{s}{ }^{*} c_{t}$, etc. are revealed as insignificant in the domain.

Quantitative analysis is made through the average effect Table 3 and the statistically significant relationship of factors and their interactions are distinguished by P-value.

In Table 4 high coefficient of determination (R-Sq) signifies the $92.66 \%$ of the response can be rendered by the input factors with $8.34 \%$ noise error and adjusted R-Sq value approves the legitimacy of the model. A higher value of $\mathrm{R}-\mathrm{Sq}$ (pred) is used to predict the model for future observations and prevent over-fitting.

The residual plots in Fig. 6 graphically elucidate the goodness of fit through the deviation in obtained and predicted data. The normal distribution of the residuals over the straight line in normal probability plot; and symmetrical

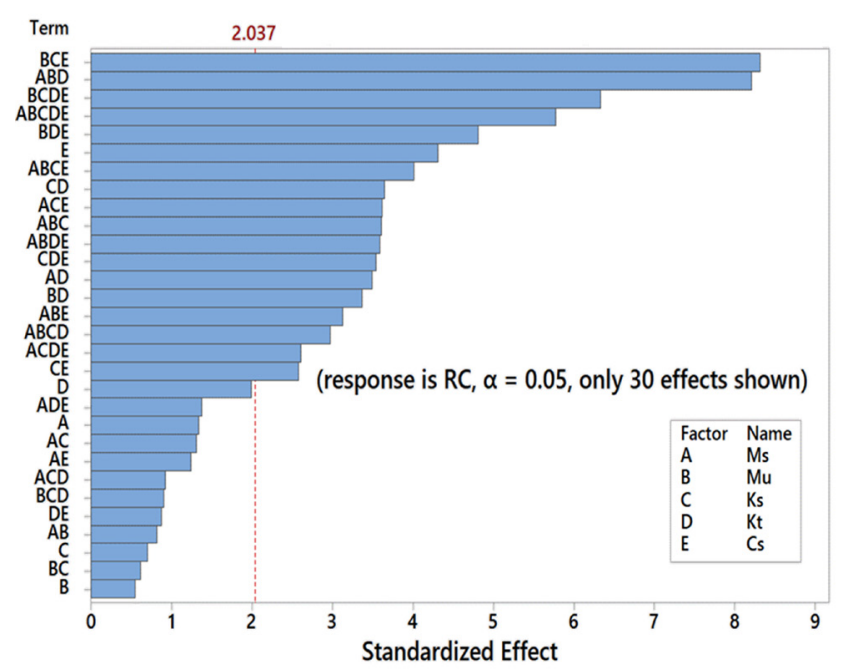

Fig. 5 Effects Pareto for RC scattering of residuals above and below the mean residual zero line in versus fits verify the homoscedasticity property. The Histogram follows a bell-shaped pattern of the normally distributed area with a little skewness due to the presence of outliers in the extreme left and right.ANOVA demonstrate the sources of influence through Table 5. The sequential sum of squares (SEQ SS) and adjusted sum of squares (AJD SS) are the two main properties that show the variance of previously presented factors to all factors presented in the model. The similarity in SEQ SS and ADJ SS proves the orthogonality of design.

The obtained regression fit model is given below:

$$
\begin{aligned}
R C= & -551.6+2.186 m_{s}+10.80 m_{u}+3.19 E-2 k_{s} \\
& +3.616 E-3 k_{t}+0.603 c_{s}-4.358 E-2 m_{s} * m_{u} \\
& -1.26 E-4 m_{s} * k_{s}-1.4 E-5 m_{s} * k_{t}-2.423 E \\
& -4 m_{s} * c_{s}-6.05 E-4 m_{u} * k_{s}-7.3 E-5 m_{u} * k_{t} \\
& -1.105 E-2 m_{u} * c_{s}-3 E-6 k_{s} * k_{t}-3.6 E \\
& -5 k_{s} * c_{s}-4 E-6 k_{t}^{*} c_{s}+2 E-6 m_{s} * m_{u} * k_{s} \\
& +2.3 E-5 m_{s} * m_{u} * k_{t}+4.6 E-5 m_{s} * m_{u} * c s \\
& +7.8 E-5 m_{s} * k_{s} * k_{t}+9 E-7 m_{s} * k_{s} * c_{s} \\
& +3.4 E-5 m_{s} * k_{t} * c_{s}+8.9 E-5 m_{u} * k_{s} * k_{t} \\
& +1.1 E-5 m_{u} * k_{s} * c_{s}+1.2 E-5 m_{u} * k_{t} * c_{s} \\
& +9 E-5 k_{s} * k_{t} * c_{s}-5 E-6 m_{s} * m_{u} * k_{s} * k_{t} \\
& -7 E-6 m_{s} * m_{u} * k_{s} * c_{s}-2.2 E \\
& -5 m_{s} * m_{u} * k_{t} * c_{s}-4.3 E-5 m_{s} * k_{s} * k_{t} * c_{s} \\
& -6.7 E-5 m_{u} * k_{s} * k_{t} * c_{s}+4.1 E \\
& -5 m_{s}^{*} m_{u} * k_{s}^{*} k_{t} * c_{s} .
\end{aligned}
$$

\section{Result and discussion}

The parameters response sensitivity examination is carried out through the individual factors and their interactions. Therefore $k_{t}$ and $c_{s}$ have been observed the most sensitive
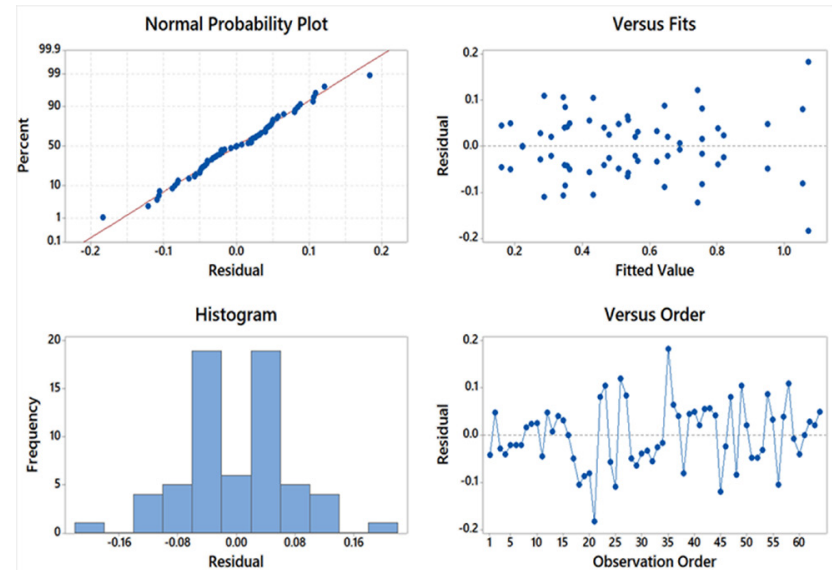

Fig. 6 Residual Plots for RC 
Table 3 Average effect

\begin{tabular}{|c|c|c|c|c|c|c|}
\hline Term & Effect & Coef & SE Coef & T-Value & P-Value & Significance \\
\hline Constant & & 0.5390 & 0.119 & 45.29 & 0.000 & Yes \\
\hline $\mathrm{m}_{\mathrm{s}}$ & -0.0318 & -0.0159 & 0.019 & -1.34 & 0.190 & No \\
\hline $\mathrm{m}_{\mathrm{u}}$ & -0.0132 & -0.0066 & 0.019 & -0.55 & 0.584 & No \\
\hline $\mathrm{k}_{\mathrm{s}}$ & -0.0167 & -0.0084 & 0.019 & -0.70 & 0.487 & No \\
\hline $\mathrm{k}_{\mathrm{t}}$ & 0.0475 & 0.0238 & 0.019 & 2.00 & 0.054 & No \\
\hline$c_{s}$ & -0.1028 & -0.0514 & 0.019 & -4.32 & 0.000 & Yes \\
\hline $\mathrm{m}_{\mathrm{s}}{ }^{*} \mathrm{~m}_{\mathrm{u}}$ & 0.0194 & 0.0097 & 0.019 & 0.82 & 0.420 & No \\
\hline $\mathrm{m}_{\mathrm{s}}{ }^{*} \mathrm{k}_{\mathrm{s}}$ & -0.0313 & -0.0156 & 0.019 & -1.31 & 0.198 & No \\
\hline $\mathrm{m}_{\mathrm{s}}{ }^{*} \mathrm{k}_{\mathrm{t}}$ & 0.0833 & 0.0416 & 0.019 & 3.50 & 0.001 & Yes \\
\hline $\mathrm{m}_{\mathrm{s}}{ }^{*} \mathrm{c}_{\mathrm{s}}$ & 0.0295 & 0.0147 & 0.019 & 1.24 & 0.225 & No \\
\hline $\mathrm{m}_{\mathrm{u}}{ }^{*} \mathrm{k}_{\mathrm{s}}$ & -0.0146 & -0.0073 & 0.019 & -0.61 & 0.543 & No \\
\hline $\mathrm{m}_{\mathrm{u}}{ }^{*} \mathrm{k}_{\mathrm{t}}$ & 0.0802 & 0.0401 & 0.019 & 3.37 & 0.002 & Yes \\
\hline $\mathrm{m}_{\mathrm{u}}{ }^{*} \mathrm{c}_{\mathrm{s}}$ & -0.0090 & -0.0045 & 0.019 & -0.38 & 0.709 & No \\
\hline $\mathrm{k}_{\mathrm{s}} * \mathrm{k}_{\mathrm{t}}$ & 0.0870 & 0.0435 & 0.019 & 3.65 & 0.001 & Yes \\
\hline $\mathrm{k}_{\mathrm{s}} * \mathrm{c}_{\mathrm{s}}$ & 0.0615 & 0.0307 & 0.019 & 2.58 & 0.015 & Yes \\
\hline $\mathrm{k}_{\mathrm{t}} * \mathrm{c}_{\mathrm{s}}$ & 0.0207 & 0.0104 & 0.019 & 0.87 & 0.390 & No \\
\hline $\mathrm{m}_{\mathrm{s}} * \mathrm{~m}_{\mathrm{u}} * \mathrm{k}_{\mathrm{s}}$ & 0.0858 & 0.0429 & 0.019 & 3.61 & 0.001 & Yes \\
\hline $\mathrm{m}_{\mathrm{s}} * \mathrm{~m}_{\mathrm{u}} * \mathrm{k}_{\mathrm{t}}$ & 0.1956 & 0.0978 & 0.019 & 8.22 & 0.000 & Yes \\
\hline $\mathrm{m}_{\mathrm{s}}{ }^{*} \mathrm{~m}_{\mathrm{u}}{ }^{*} \mathrm{c}_{\mathrm{s}}$ & -0.0746 & -0.0373 & 0.019 & -3.13 & 0.004 & Yes \\
\hline $\mathrm{m}_{\mathrm{s}} * \mathrm{k}_{\mathrm{s}} * \mathrm{k}_{\mathrm{t}}$ & -0.0220 & -0.0110 & 0.019 & -0.92 & 0.362 & No \\
\hline $\mathrm{m}_{\mathrm{s}}{ }^{*} \mathrm{k}_{\mathrm{s}}{ }^{*} \mathrm{c}_{\mathrm{s}}$ & 0.0862 & 0.0431 & 0.019 & 3.62 & 0.001 & Yes \\
\hline $\mathrm{m}_{\mathrm{s}} * \mathrm{k}_{\mathrm{t}} * \mathrm{c}_{\mathrm{s}}$ & -0.0327 & -0.0164 & 0.019 & -1.38 & 0.178 & No \\
\hline $\mathrm{m}_{\mathrm{u}} * \mathrm{k}_{\mathrm{s}} * \mathrm{k}_{\mathrm{t}}$ & 0.0215 & 0.0107 & 0.019 & .90 & 0.374 & No \\
\hline $\mathrm{m}_{\mathrm{u}} * \mathrm{k}_{\mathrm{s}}{ }^{*} \mathrm{c}_{\mathrm{s}}$ & -0.1979 & -0.0990 & 0.019 & -8.32 & 0.000 & Yes \\
\hline $\mathrm{m}_{\mathrm{u}}{ }^{*} \mathrm{k}_{\mathrm{t}}{ }^{*} \mathrm{c}_{\mathrm{s}}$ & -0.1145 & -0.0572 & 0.019 & -4.81 & 0.000 & Yes \\
\hline $\mathrm{k}_{\mathrm{s}}{ }^{*} \mathrm{k}_{\mathrm{t}}{ }^{*} \mathrm{c}_{\mathrm{s}}$ & 0.0843 & 0.0421 & 0.019 & 3.54 & 0.001 & Yes \\
\hline $\mathrm{m}_{\mathrm{s}}^{*} \mathrm{~m}_{\mathrm{u}} * \mathrm{k}_{\mathrm{s}}{ }^{*} \mathrm{k}_{\mathrm{t}}$ & -0.0709 & -0.0354 & 0.019 & -2.98 & 0.005 & Yes \\
\hline $\mathrm{m}_{\mathrm{s}} * \mathrm{~m}_{\mathrm{u}} * \mathrm{k}_{\mathrm{s}}^{*} \mathrm{c}_{\mathrm{s}}$ & 0.0957 & 0.0478 & 0.019 & 4.02 & 0.000 & Yes \\
\hline $\mathrm{m}_{\mathrm{s}}^{*} \mathrm{~m}_{\mathrm{u}} * \mathrm{k}_{\mathrm{t}}^{*} \mathrm{c}_{\mathrm{s}}$ & -0.0855 & -0.0428 & 0.019 & -3.59 & 0.001 & Yes \\
\hline $\mathrm{m}_{\mathrm{s}}^{*} \mathrm{k}_{\mathrm{s}}^{*} \mathrm{k}_{\mathrm{t}}^{*} \mathrm{c}_{\mathrm{s}}$ & -0.0621 & -0.0310 & 0.019 & -2.61 & 0.014 & Yes \\
\hline $\mathrm{m}_{\mathrm{u}}{ }^{*} \mathrm{k}_{\mathrm{s}} * \mathrm{k}_{\mathrm{t}}^{*} \mathrm{c}_{\mathrm{s}}$ & 0.1508 & 0.0754 & 0.019 & 6.33 & 0.000 & Yes \\
\hline $\mathrm{m}_{\mathrm{s}}^{*} \mathrm{~m}_{\mathrm{u}}^{*} \mathrm{k}_{\mathrm{s}}^{*} \mathrm{k}_{\mathrm{t}}^{*} \mathrm{c}_{\mathrm{s}}$ & 0.3174 & 0.0687 & 0.019 & 5.77 & 0.000 & Yes \\
\hline
\end{tabular}

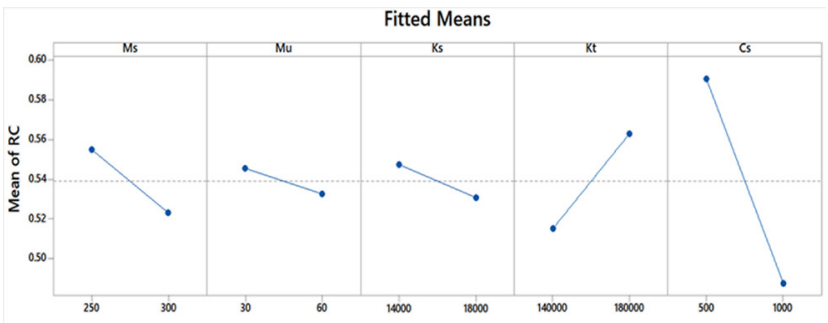

Fig. 7 Main Effects Plot for RC

parameters in the domain from the slopes in Fig. 7. Similarly the parameters interaction terms $m_{u} * k_{s}, m_{s} * k_{s}$ and $k_{s} * k_{t}$ are found highly sensitive from the slopes shown in Fig. 8.
Table 4 Regression Statistics

\begin{tabular}{lcc}
\hline $\mathrm{S}$ & Standard Error of Regression & 0.0951978 \\
\hline $\mathrm{R}-\mathrm{Sq}$ & Coefficient of Determination & $92.66 \%$ \\
$\mathrm{R}-\mathrm{Sq}($ adj) & Adjusted Coefficient of Determination & $90.55 \%$ \\
$\mathrm{R}-\mathrm{Sq}$ (pred) & Predicted Coefficient of Determination & $89.65 \%$ \\
\hline
\end{tabular}

The objective of minimization to the desired behavior of the plant is RMS acceleration; where the user has been selected $0.5 \mathrm{~m} / \mathrm{s}^{2}$ and $0.315 \mathrm{~m} / \mathrm{s}^{2}$ are the upper extreme response value and target values respectively. Further, the optimum parametric setting is revealed in Fig. 9. 
Table 5 ANOVA

\begin{tabular}{lcccccc}
\hline Source & DF & SEQ SS & ADJ SS & ADJ MS & F-Value & P-Value \\
\hline Model & 31 & 3.66236 & 3.66236 & 0.118140 & 13.04 & 0.000 \\
Main Effects & 5 & 0.22859 & 0.22859 & 0.045718 & 5.04 & 0.002 \\
2-Way Interactions & 10 & 0.44256 & 0.44256 & 0.044256 & 4.88 & 0.000 \\
3-Way Interactions & 10 & 1.91991 & 1.91991 & 0.191991 & 21.18 & 0.000 \\
4-Way Interactions & 5 & 0.76916 & 0.76916 & 0.153832 & 16.97 & 0.000 \\
5-Way Interactions & 1 & 0.30213 & 0.30213 & 0.302129 & 33.34 & 0.000 \\
Residual Error & 32 & 0.29000 & 0.29000 & 0.009063 & & \\
\hline Total & 63 & 3.95236 & & & &
\end{tabular}

Fitted Means

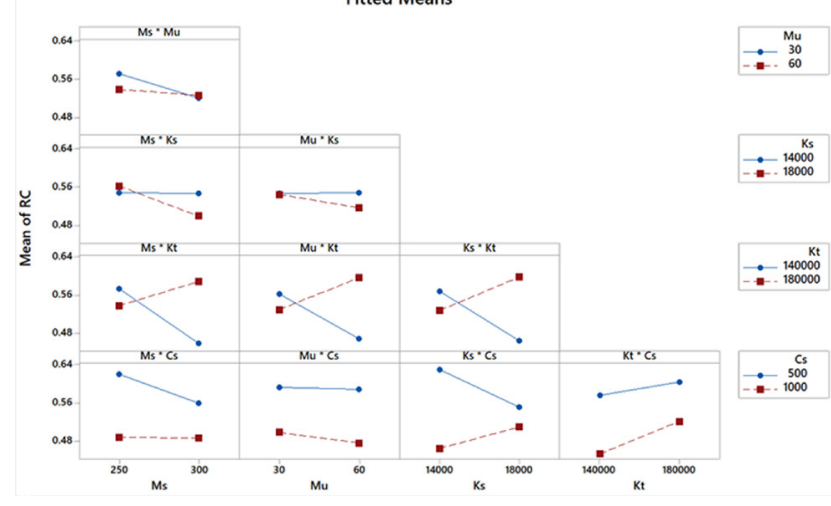

Fig. 8 Interaction Plot for RC

The RMS acceleration data obtained from the experimentations conducted at test rig at the optimized design setting of suspension system is $0.2267 \mathrm{~m} / \mathrm{s}^{2}$ with an accuracy of $70.09 \%$. Furthermore, the results carried forward to the developed MATLAB-SIMULINK model. The RC value obtained at Simulink test was $0.2043 \mathrm{~m} / \mathrm{s}^{2}$ with an accuracy of $77.77 \%$. The final results are concluded in Table 6 .

\section{Conclusions}

The experimental study has been carried out to optimize the passenger vehicle suspension system design using a quarter car test model subjected to the random road inputs. The objective was to minimize the body vibrations for the optimum parametric values of the components. The linear and nonlinear characteristics of the suspension components have been examined through the experimen-

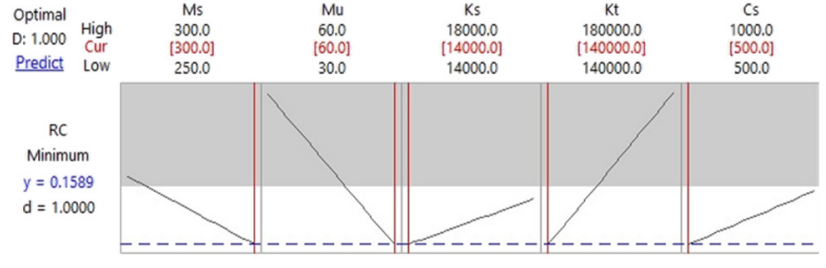

Fig. 9 Optimization Plot

tations conducted at the fabricated quarter car test rig. Full factorial design of experiments methodology has been explored through the 64 set of experiments to get the optimum setting of the design parameters. All the experiments have been simulated in MATLAB-SIMULINK which save the huge time and cost of experimentations. The obtained value of optimum design finally validated on the test rig with $70.09 \%$ accuracy. The experimental model exhibited a consistent result of R-Sq-92.66\%, R-Sq(adj)-90.55\%, and $\mathrm{R}-\mathrm{Sq}$ (pred)-89.65\% which explains the variability, reliability, and predictability of the model. A desirable value of RMS acceleration $0.1589 \mathrm{~m} / \mathrm{s}^{2}$ has been obtained at the optimized design. The various other parameters, related to suspension system geometry such like toe, camber, caster, tire pressure, etc., can be included in further analysis to improve the quantified results in terms of R-Sq, R-Sq(adj), and R-Sq(pred). To make the experimental process more economical, the number of runs can be reduced by considering the fraction factorial method of DOE where main effects are only confounded with 4-way interactions and higher.

Table 6 Optimized Settings with Results

\begin{tabular}{|c|c|c|c|c|c|c|c|}
\hline Response & Goal & Target & Upper & Weight & Importance & & \\
\hline $\mathrm{RC}$ & Minimum & 0.315 & 0.5 & 1 & 1 & & \\
\hline \multirow[t]{2}{*}{ Solution } & $m_{s}$ & $m_{u}$ & $k_{s}$ & $k_{t}$ & $c_{s}$ & RC Fit & $\begin{array}{l}\text { Composite } \\
\text { Desirability }\end{array}$ \\
\hline & 300 & 60 & 14000 & 140000 & 500 & 0.1589 & 1 \\
\hline
\end{tabular}




\section{References}

Alkhatib, R., Nakhaie Jazar , G., Golnaraghi, M. (2004) "Optimal design of passive linear suspension using genetic algorithm", Journal of Sound and Vibration, 275(3-5), pp. 665-691. https://doi.org/10.1016/j.jsv.2003.07.007

Avesh, M., Srivastava, R. (2012) "Modeling simulation and control of active suspension system in Matlab Simulink environment", In: Students Conference on Engineering and Systems, Allahabad, India, pp. 1-6.

https://doi.org/10.1109/SCES.2012.6199124

Avesh, M., Srivastava, R. (2019) "Passenger Car Active Suspension System Model for Better Dynamic Characteristics", National Academy Science Letters, pp. 1-5. https://doi.org/10.1007/s40009-019-00807-z

Cao, D., Song, X. Ahmadian, M. (2011) "Editors' perspectives: road vehicle suspension design, dynamics, and control", Vehicle System Dynamics, 49(1-2), pp. 3-28. https://doi.org/10.1080/00423114.2010.532223

Chi, Z., He, Y. (2008) "Design optimization of vehicle suspensions with a quarter-vehicle model" Transactions of the CSME, 32(2), pp. 297312. [online] Available at: https://www.tcsme.org/Papers/Vol32/ Vol32No2Paper11.pdf [Accessed: 14 July 2018]

Christensen, B. G., Ferris, J. B., Stein, J. L. (2000) "An energy-enhanced design of experiments method applied to multi-body models", In: Proceedings of the 2000 ASME International Mechanical Engineering Congress and Exposition, Orlando, FL, USA, pp. 5-10.

Craft, M. J., Buckner, G. D., Anderson, R. D. (2003) "Semi-active vehicle shock absorbers: design and experimental evaluations", In: Proceedings of SPIE - The International Society for Optical Engineering, SPIE, pp. 5777-588.

Czitrom, V. (1999) "One-Factor-at-a-Time versus Designed Experiments", The American Statistician, 53(2), pp. 126-131. https://doi.org/10.1080/00031305.1999.10474445

Gobbi, M., Mastinu, G. (2001) "Analytical description and optimization of the dynamic behaviour of passively suspended road vehicles", Journal of Sound and Vibration, 245(3), pp. 457-481. https://doi.org/10.1006/jsvi.2001.3591

Hemanth, K., Kumar, H., Gangadharan, K. V. (2017) "Vertical dynamic analysis of a quarter car suspension system with MR damper", Journal of the Brazilian Society of Mechanical Sciences and Engineering, 39(1), pp. 41-51. https://doi.org/10.1007/s40430-015-0481-7

Hyniova, K., Stribrsky, A., Honcu, J., Kruczek, A. (2009) "Active Suspension System-Energy Control", IFAC Proceedings Volumes, 42(19), pp. 146-152.

https://doi.org/10.3182/20090921-3-TR-3005.00027

International Organization for Standardization (1995) "ISO 8608(E) Mechanical Vibration-Road Surface Profiles-Reporting of Measured Data", ISO, Geneva, Switzerland.

International Organization for Standardization (1997) "ISO 2631(1) Mechanical vibration and shock-Evaluation of human exposure to whole-body vibration-Part 1: General requirements", ISO, Geneva, Switzerland.
Kjellberg, A. (1990) "Psychological aspects of occupational vibration", Scandinavian Journal of Work and Environmental Health, 16(Suppl. 1), pp. 39-43. [online] Available at: http://www.jstor.org/ stable/40965842 [Accessed: 10 February 2018]

Metered, H., Kozek, M., Šika, Z. (2015) "Vibration control of active vehicle suspension using fuzzy based sliding surface", International Journal of Fuzzy Systems and Advanced Applications, 2, pp. 41-48.

Nagarkar, M. P., Vikhe Patil, G. J., Zaware Patil, R. N. (2016) "Optimization of nonlinear quarter car suspension-seat-driver model", Journal of Advanced Research, 7(6), pp. 991-1007. https://doi.org/10.1016/j.jare.2016.04.003

Nagy, D., Gáspár, P. (2012) "Active suspension control design for unmanned ground vehicles", Periodica Polytechnica Transportation Engineering, 40(1), pp. 27-32. https://oi.org/10.3311/pp.tr.2012-1.05

Németh, B., Gáspár, P. (2017) "Nonlinear analysis and control of a variable-geometry suspension system", Control Engineering Practice, 61, pp. 279-291. https://doi.org/10.1016/j.conengprac.2016.09.015

Poussot-Vassal, C., Sename, O., Dugard, L., (2008) "The design of a chassis system based on multi-objective qLPV control", Periodica Polytechnica Transportation Engineering, 36(1-2), pp. 93-97. https://doi.org/10.3311/pp.tr.2008-1-2.17

Salah, A., Abbas, W., Abouelatta, O. B. (2012) "Design of Optimal Linear Suspension for Quarter Car with Human Model using Genetic Algorithms", The Research Bulletin of Jordan ACM, II(II), pp. 42-51. [online] Available at: https://pdfs.semanticscholar.org/30cd/cc0ff33521ee6fdccd364b3dd7d8349e8781.pdf [Accessed: 10 February 2018]

Sharma, S. K., Chaturvedi, S. (2016) "Jerk analysis in rail vehicle dynamics", Perspectives in Science, 8, pp. 648-650. https://doi.org/10.1016/j.pisc.2016.06.047

Sharma, S. K., Kumar, A. (2017a) "Impact of electric locomotive traction of the passenger vehicle Ride quality in longitudinal train dynamics in the context of Indian railways", Mechanics \& Industry, 18(2), Article Number 222. https://oi.org/10.1051/meca/2016047

Sharma, S. K., Kumar, A. (2017b) "Ride performance of a high speed rail vehicle using controlled semi active suspension system", Smart Materials and Structures, 26(5), ID: 055026. https://doi.org/10.1088/1361-665X/aa68f7

Sharma, S. K., Sharma, R. C., Kumar, A., Palli, S. (2015) "Challenges in Rail Vehicle-Track Modeling and Simulation", International Journal of Vehicle Structures and Systems, 7(1), pp. 1-9. https://doi.org/10.4273/ijvss.7.1.01

Shirahatti., A., Prasad, P. S. S., Panzade, P., Kulkarni, M. M. (2008) "Optimal design of passenger car suspension for ride and road holding", Journal of the Brazilian Society of Mechanical Sciences and Engineering, 30(1), pp. 66-76. https://doi.org/10.1590/S1678-58782008000100010 
Sun, L., Cai, X., Yang, J. (2007) "Genetic algorithm-based optimum vehicle suspension design using minimum dynamic pavement load as a design criterion", Journal of Sound and Vibration, 301(1-2), pp. $18-27$.

https://doi.org/10.1016/j.jsv.2006.08.040

Tamboli, J. A., Joshi, S. G. (1999) "Optimum design of a passive suspension system of a vehicle subjected to actual random road excitations", Journal of Sound and Vibration, 219(2), pp. 193-205. https://doi.org/10.1006/jsvi.1998.1882

Tewari, V. K., Prasad, N. (1999) "Three-DOF modelling of tractor seat-operator system", Journal of Terramechanics, 36(4), pp. 207-219.

https://doi.org/10.1016/S0022-4898(99)00008-7
Yu, M., Liao, C. R., Chen, W. M., Huang, S. L. (2006) "Study on MR Semi-active Suspension System and its Road Testing", Journal of Intelligent Material Systems and Structures, 17(8-9), pp. 801-806. https://doi.org/10.1177/1045389X06057534

Zuo, L., Zhang, P-S. (2013) "Energy Harvesting, Ride Comfort, and Road Handling of Regenerative Vehicle Suspensions", Journal of Vibration and Acoustics, 135(1), ID: 011002 https://doi.org/10.1115/1.4007562 